\title{
Thrombocytopenia during pregnancy: an institutional based study
}

\section{Rajshree Dayanand Katke*, Dhruv Pravin Gohil}

Department of Obstetrics \& Gynaecology, Cama and Albless Hospital, Sir J.J Group of Hospitals, Mumbai, MH, India

Received: 30 August 2014

Revised: 8 September 2014

Accepted: 29 September 2014

\author{
*Correspondence: \\ Dr. Rajshree Dayanand Katke, \\ E-mail: drrajshreekatke@gmail.com
}

Copyright: ( $)$ the author(s), publisher and licensee Medip Academy. This is an open-access article distributed under the terms of the Creative Commons Attribution Non-Commercial License, which permits unrestricted non-commercial use, distribution, and reproduction in any medium, provided the original work is properly cited.

\begin{abstract}
Background: Thrombocytopenia affects $6 \%$ to $10 \%$ of all pregnant women and other than anemia is the most common hematologic disorder in pregnancy. All pregnant women with platelet counts less than $100000 / \mathrm{mm}^{3}$ require careful hematological and obstetric consultation to exclude more serious disorders. Objectives of the study were to study the number and percentage of cases, the various etiological factors associated, the effect and outcome of the mother and neonates borne.

Methods: The study was conducted in this tertiary institute over a period of two years and three months. 103 pregnant patients with a platelet count of or less than $100000 / \mathrm{mL}$ were included. The course of pregnancy was studied and the investigation profile was monitored.

Results: Out of 103 cases of thrombocytopenia, 73 (70.9\%) patients had moderate, $30(29.1 \%)$ patients had severe thrombocytopenia. In this study 35\% cases were primigravidas, $32 \%$ cases were gravida 2, 33\% cases were gravida 3 to 5. Gestational thrombocytopenia was the most common etiological factor with $30.1 \%$ cases, $27.2 \%$ cases due to hypertensive disorders, $18.4 \%$ cases due to malaria followed by $12.6 \%$ cases due to dengue. In the study group the mean gestational age was $33 \pm 5.139$, maximum cases belonged to gestational age 30 to $\geq 40.14$ patients $(14.1 \%)$ had still births. 9 patients $(8.7 \%$ ) had Neonatal deaths (NNDs).

Conclusions: The challenge to the clinician is to weigh the risks of maternal and fetal bleeding complications against the benefits of diagnostic tests and interventions.
\end{abstract}

Keywords: Thrombocytopenia, Pregnancy

\section{INTRODUCTION}

Pregnancy is associated with physiological and pathological changes in platelet numbers and function which can be of clinical concern. Inherited defects in platelet function and number may also manifest during pregnancy with the risk of bleeding dependent on the underlying problem. Thrombocytopenia affects $6 \%$ to $10 \%$ of all pregnant women and other than anemia is the most common hematologic disorder in pregnancy.

Recent studies have demonstrated that the mean and $2.5^{\text {th }}$ percentile platelet count decreases by approximately $10 \%$ in pregnant patients, and that the histogram of platelet count distribution at term is normally distributed but shifted to the left. ${ }^{1,2}$ In most cases, this "physiologic" decrease in platelets occurs in the third trimester. Thrombocytopenia in pregnancy may occur secondary to a variety of causes ranging from benign disorders such as gestational thrombocytopenia to syndromes associated with significant morbidity such as eclampsia, HELLP, ITP, TTP-HUS. Other causes of thrombocytopenia in pregnancy are rare such as Type II von Wiillebrand Disease (vWD), and disseminated intravascular coagulation. All pregnant women with platelet counts less than $100000 / \mathrm{mL}$ require careful hematological and obstetric consultation to exclude more serious disorders. 


\section{Aims and objectives of the study}

1. To study the number and percentage of cases of moderate and severe thrombocytopenia in pregnancy.

2. To study the various etiological factors associated with thrombocytopenia in pregnancy.

3. To study the different diseases in which thrombocytopenia manifests in ANC patients.

4. To study the effect and outcome of the mother and neonates borne to them.

5. To study the management of cases of thrombocytopenia in pregnancy.

6. To study the morbidity and mortality associated with thrombocytopenia in pregnancy.

\section{METHODS}

Inclusion criteria: All pregnant patients with a platelet count equal to or below 100000 per micro-litre were included in the study.

The study was conducted in the tertiary institute over a period of two years and three months, from September 2010 to November 2012. 103 pregnant patients with a platelet count of or less than $100000 / \mathrm{mL}$ were included in the study group. Patients from all trimesters of pregnancy were included. On admission a thorough history was taken and a detailed clinical examination was carried out. All the patients were subjected to biochemical investigations, special investigations and ultrasonography.

Patients were grouped into 2 categories - one with moderate thrombocytopenia (platelet count $>50000$ or less than or equal to $100000 / \mathrm{ml}$ and one with severe thrombocytopenia (platelet count equal to or less than $50000 / \mathrm{ml})$.

The course of pregnancy was studied and the investigation profile was monitored. The obstetric outcome was noted. The entire hospital stay course was noted. Final outcome of all cases and complications if any was statistically studied.

\section{RESULTS}

Out of the 103 cases, 30 cases $(29.1 \%)$ had severe thrombocytopenia and 73 cases $(70.9 \%)$ had moderate thrombocytopenia (Table 1).

Table 1: Distribution of moderate and severe thrombocytopenia cases.

\begin{tabular}{|lll|}
\hline Platelets $(50000$ cut-ofif) & No. & Percentage \\
\hline Severe TCP $(\leq 50000)$ & 30 & $29.1 \%$ \\
\hline Moderate TCP $(>50000)$ & 73 & $70.9 \%$ \\
\hline Total & 103 & $100.0 \%$ \\
\hline
\end{tabular}

In this study $34 \%$ cases were of 20-23 weeks of gestation, $31.1 \%$ cases were of $24-27$ weeks of gestation, $18.4 \%$ cases were of 20-23 weeks of gestation, $8.7 \%$ cases were of 32-35 weeks of gestation, $4.9 \%$ cases were of less than 20 weeks of gestation, $2.9 \%$ cases were of $\geq 36$ weeks of gestation (Table 2).

In this study $35 \%$ cases were primigravidas, $32 \%$ cases were gravida $2,33 \%$ cases were gravida 3 to 5 .

Table 2: Distribution of cases according to weeks of gestation.

\begin{tabular}{|lll|}
\hline $\begin{array}{l}\text { Weeks of } \\
\text { gestation }\end{array}$ & No. & Percentage \\
\hline$<20$ & 6 & $5.8 \%$ \\
\hline 20 to 24 & 10 & $9.7 \%$ \\
\hline 25 to 29 & 9 & $8.7 \%$ \\
\hline 30 to 34 & 28 & $27.2 \%$ \\
\hline 35 to 39 & 46 & $44.7 \%$ \\
\hline$\geq 40$ & 4 & $3.9 \%$ \\
\hline Total & 103 & $100.0 \%$ \\
\hline
\end{tabular}

Table 3: Distribution of cases according to etiology.

\begin{tabular}{|lll|}
\hline Etiology & No. & Percentage \\
\hline Gestational thrombocytopenia & 31 & $30.1 \%$ \\
\hline Malaria & 19 & $18.4 \%$ \\
\hline Dengue & 13 & $12.6 \%$ \\
\hline Pregnancy induced hypertension & 13 & $12.6 \%$ \\
\hline Eclampsia & 9 & $8.7 \%$ \\
\hline $\begin{array}{l}\text { HELLP (Syndrome of haemolysis, } \\
\text { elevated liver enzymes, low platelets) }\end{array}$ & 6 & $5.8 \%$ \\
\hline Antepartum haemorrhage & 4 & $3.9 \%$ \\
\hline Renal disease & 2 & $1.9 \%$ \\
\hline Acute respiratory distress syndrome & 1 & $1.0 \%$ \\
\hline Idiopathic thrombocytopenic purpura & 1 & $1.0 \%$ \\
\hline Leptospirosis & 1 & $1.0 \%$ \\
\hline Multiorgan failure & 1 & $1.0 \%$ \\
\hline Septicaemia & 1 & $1.0 \%$ \\
\hline Stroke & 1 & $1.0 \%$ \\
\hline Total & 103 & $100.0 \%$ \\
\hline
\end{tabular}

In this study gestational thrombocytopenia was the most common etiological factor with $30.1 \%$ cases followed by $18.4 \%$ for malaria followed by $12.6 \%$ for dengue, $16.6 \%$ for pregnancy induced hypertension, $8.7 \%$ for eclampsia, $5.8 \%$ cases for HELLP syndrome.

$37.9 \%$ cases of severe thrombocytopenia had deranged liver function tests and $6.8 \%$ cases of moderate thrombocytopenia had deranged liver function tests. The association of deranged LFTs with severe thrombocytopenia was statistically significant (Pearson Chi square $\mathrm{P}=0.000099$ ). In this study $8.8 \%$ cases had deranged renal function tests. $91.2 \%$ cases had renal function tests within normal limit.

$24.1 \%$ cases of severe thrombocytopenia and $2.7 \%$ cases of moderate thrombocytopenia had deranged RFTs. The 
association of deranged RFTs with severe thrombocytopenia was statistically significant (Pearson Chi square $\mathrm{P}=0.00059$ ).

In this study out of the malaria cases, $73.88 \%$ cases had P. vivax Malaria, $15.78 \%$ cases had mixed malaria and $10.5 \%$ cases had P. falciparum malaria.

Among the 12 cases of dengue in this study, 50\% were IgM positive, $42.8 \%$ were NS1Ag positive, $7.2 \%$ cases were $\mathrm{IgG}$ positive.

Table 4: Route of delivery among the cases.

\begin{tabular}{|lll|}
\hline Route of delivery & No. & Percentage \\
\hline $\begin{array}{l}\text { Full term vaginal delivery with } \\
\text { episiotomy }\end{array}$ & 25 & $24.27 \%$ \\
\hline $\begin{array}{l}\text { Full term vaginal delivery without } \\
\text { episiotomy }\end{array}$ & 25 & $24.27 \%$ \\
\hline Lower segment caesarean section & 25 & $24.27 \%$ \\
\hline Preterm vaginal delivery & 22 & $21.35 \%$ \\
\hline Spontaneous abortion & 4 & $3.88 \%$ \\
\hline $\begin{array}{l}\text { Lower segment caesarean section } \\
\text { with obstetric hysterectomy }\end{array}$ & 1 & $0.97 \%$ \\
\hline $\begin{array}{l}\text { Lower segment caesarean section } \\
\text { with obstetric hysterectomy with } \\
\text { internal iliac ligation }\end{array}$ & 1 & $0.97 \%$ \\
\hline Total & 103 & $100.0 \%$ \\
\hline
\end{tabular}

The route of delivery of the 102 cases was full term vaginal delivery with episiotomy in $24.27 \%$ cases, full term vaginal delivery without episiotomy in $24.27 \%$ cases, LSCS in $24.27 \%$ cases, preterm vaginal delivery in $21.35 \%$ cases, $3.88 \%$ spontaneous abortions.

1 case required LSCS with obstetric hysterectomy and one case required LSCS with obstetric hysterectomy with internal iliac ligation.

In this study $7.1 \%$ cases had fresh still births and $7.1 \%$ cases had macerated still births. In this study among the severe thrombocytopenia cases $24.6 \%$ had still births and among the moderate thrombocytopenia cases $8.6 \%$ had still births.

The association of still births with severe thrombocytopenia was statistically significant (Pearson Chi square test $\mathrm{P}=0.01347$ ).

In this study out of 103 cases there were $9(8.7 \%)$ neonatal deaths. In the severe thrombocytopenia group there were $20 \%$ neonatal and in the moderate thrombocytopenia group there were $4.1 \%$ neonatal deaths. The association between NNDs and severe thrombocytopenia was statistically significant (Pearson Chi square test $\mathrm{P}=0.0095$ ).
Table 5: Observations of cases of neonatal deaths.

\begin{tabular}{|ll|}
\hline Total neonatal deaths & $\begin{array}{c}\text { Number } \\
\text { of cases }\end{array}$ \\
\hline Weeks of gestation & 9 \\
\hline$\leq 29$ weeks & 2 \\
\hline $30-34$ weeks & 3 \\
\hline$\geq 35$ weeks & 4 \\
\hline Etiology of cases & \\
\hline Eclampsia & 3 \\
\hline HELLP & 2 \\
\hline APH & 3 \\
\hline GT & 3 \\
\hline Malaria & 1 \\
\hline TCP category & \\
\hline Moderate & 3 \\
\hline Severe & 6 \\
\hline Route of delivery & \\
\hline Vaginal & 9 \\
\hline Caesarean & 0 \\
\hline APGAR score & \\
\hline 1 min $\leq 7$ & 5 \\
\hline 5 min $\leq 7$ & 5 \\
\hline Cause of NND & 3 \\
\hline Birth asphyxia & 5 \\
\hline Pneumonia & \\
\hline Cardio respiratory arrest & 5 \\
\hline
\end{tabular}

Table 6: Analysis of platelet transfusions.

\begin{tabular}{|ll|}
$\begin{array}{l}\text { No. of cases requiring platelet } \\
\text { transfusion (All cases) }\end{array}$ & 36 \\
\hline Mean \pm SD & $4.78 \pm 3.296$ \\
\hline Median & 4 \\
\hline Minimum & 2 \\
\hline Maximum & 20 \\
\hline
\end{tabular}

In this study the number of mortalities were seen were 8 (7.76\% of cases). 5 cases belonged to the severe thrombocytopenia group. The association of mortality with severe thrombocytopenia was statistically significant. The cause for mortality in these 6 cases were one each due to acute respiratory distress syndrome, haemothorax with liver failure, intracranial bleed, cardiorespiratory arrest, hypotension? Pulmonary embolism, kidney failure, multiorgan failure, stroke.

\section{DISCUSSION}

In a prospective study of over 27 months all pregnant patients with thrombocytopenia with platelet count less than or equal to one lakh per $\mathrm{mL}$ were included .Their detailed history, examination findings, investigations were noted. Course of pregnancy was followed up and the maternal, obstetric and fetal outcome was noted. 
The study included 103 cases of thrombocytopenia with platelet count less than or equal to one lakh, who were admitted in our tertiary public hospital were included in the study group.

Out of 103 cases of thrombocytopenia, 73 (70.9\%) patients had moderate (platelet count >50000), 30 $(29.1 \%)$ patients had severe thrombocytopenia (platelet count $\leq 50000$ ).

In this study $35 \%$ cases were primigravidas, $32 \%$ cases were gravida $2,33 \%$ cases were gravida 3 to 5 .

Maximum incidence of cases being in 20 to 27 years age group with mean age $27.57 \pm 5.64$ years in the study group as opposed to a study by Parnas et al. in $2006^{3}$ the mean age was $30.7 \pm 5.9$.

Gestational thrombocytopenia was the most common etiological factor with $30.1 \%$ cases followed by $27.2 \%$ for hypertensive disorders including HELLP syndrome followed by $18.4 \%$ for Malaria followed by $12.6 \%$ for dengue. The most important etiological factors for thrombocytopenia are gestational thrombocytopenia accounting for $59.3 \%$ followed by hypertensive disorders $21.1 \%$ followed by ITP $11.05 \%$ as studied by M. Parnas et al. in $2006 .^{3}$

In the study group the mean gestational age was $33 \pm$ 5.139, maximum cases belonged to gestational age 30 to $\geq 40$ weeks as compared to the study of Parnas et al. in $2006^{3}$ in which maximum patients $74.4 \%$ belonged to 37 to $40+$ weeks gestation.

Out of 103 patients, 19 patients had malaria. In this study out of the malaria cases, $73.88 \%$ cases had P. vivax Malaria, $15.78 \%$ cases had mixed malaria and $10.5 \%$ cases had P. falciparum malaria. Out of 4 mixed infection cases, $3(75 \%)$ belonged to the severe thrombocytopenia group. Severe thrombocytopenia was seen in 2 out of 14 cases of $P$. vivax and 1 out of 2 cases of $P$. falciparum.

14 patients $(13.5 \%)$ had Dengue, out of which $7(50 \%)$ cases were $\operatorname{IgM}$ positive, $1(7.2 \%)$ was $\operatorname{IgG}$ positive, 6 cases $(42.8 \%)$ were NS1Ag. 2 out of 7 cases of IgM positive, 2 out of 6 cases of NS1Ag positive belonged to severe thrombocytopenia group.

The route of delivery of the 103 cases was full term vaginal delivery with episiotomy in $24.27 \%$ cases, full term vaginal delivery without episiotomy in $24.5 \%$ cases, LSCS in $24.27 \%$ cases, preterm vaginal delivery in $21.35 \%$ cases, $3.88 \%$ spontaneous abortions. 1 case required LSCS with obstetric hysterectomy and one case required LSCS with Obstetric Hysterectomy with internal iliac ligation.

11 patients $(10.9 \%)$ had preterm deliveries out of which 3 patients $(27.27 \%)$ belonged to the severe thrombocytopenia group. The association of preterm deliveries with severe thrombocytopenia was not statistically significant.

3 patients $(3 \%)$ had spontaneous abortion and underwent check curettage and all patients belonged to the nonsevere thrombocytopenia group

14 patients $(14.1 \%)$ had still births as opposed to the study of Parnas et al. in $2006^{3}$ where $6.5 \%$ cases had still births. Out of that 8 patients $(57.14 \%)$ belonged to the severe thrombocytopenia group.6 patients $(42.85 \%)$ belonged to non-severe thrombocytopenia group. The association of still births with severe thrombocytopenia was statistically significant. (Pearson Chi square test $\mathrm{P}=$ $0.01347)$.

There were 7 fresh still births out of which 1 occurred at $<29$ weeks of gestation, 4 occurred at 30-34 weeks of gestation and 2 at 35-39 weeks of gestation. 3 cases had moderate thrombocytopenia and 4 had severe thrombocytopenia. 3 cases occurred in eclampsia patients, 1 case in HELLP syndrome patient, one in ARDS patient, one in a patient of septicaemia.

There were 7 macerated still births out of which 6 occurred at 35-39 weeks gestation and one at 30-34 weeks gestation. 4 cases had severe thrombocytopenia and 3 cases had moderate thrombocytopenia, 2 occurred in patients of PIH, one in a patient of HELLP syndrome and 3 in patients of APH.

27 patients $(26.47 \%)$ underwent a caesarean section due to obstetric indications as opposed to the study of Parnas et al. in $2006^{3}$ in which $36.2 \%$ patients underwent a caesarean section, out of which 19 patients $(70.37 \%)$ belonged to non-severe thrombocytopenia group and 8 patients $(29.62 \%)$ belonged to the severe thrombocytopenia group. The association of LSCS with severe thrombocytopenia was not statistically significant.

9 patients $(8.7 \%)$ had neonatal deaths (NNDs) as opposed to the study of Parnas et al. in $2006^{3}$ in which $2.5 \%$ patients has NNDs. Out of that 6 patients $(66.66 \%)$ belonged to the severe thrombocytopenia group. The association of NNDs with severe thrombocytopenia was statistically significant (Pearson Chi square test $\mathrm{P}=$ 0.0095). 5 NNDs occurred due to cardiorespiratory arrest, 3 due to birth asphyxia and one due to pneumonia.5 neonates had APGAR score of $<7$ at 1 minutes as well as 5 minutes. 2 occurred in patients at $<29$ weeks of gestation, 4 in patients $>35$ weeks of gestation and 3 in patients at 3-34 weeks of gestation. 3 NNDs occurred in Gestational thrombocytopenia patients, one in a malaria patient, 2 in patients with HELLP syndrome and 3 in patients with eclampsia.

In this study the number of mortalities were seen were 8 (7.76\% of cases). 5 cases belonged to the severe thrombocytopenia group. The association of mortality with severe thrombocytopenia was statistically significant. The cause for mortality in these 6 cases were 
one each due to acute respiratory distress syndrome, haemothorax with liver failure, intracranial bleed, cardiorespiratory arrest, hypotension? Pulmonary embolism, kidney failure, multiorgan failure, stroke.

In this study oligohydramnios was seen in $5.8 \%$ of cases as opposed to the study of Parnas et al. in $2006^{3}$ where it was seen in $1.5 \%$ of cases. In this this study $4.8 \%$ cases had placenta previa as opposed to the study of Parnas et al in $2006^{3}$ where $2.5 \%$ cases had placenta previa.

\section{CONCLUSION}

Thrombocytopenia affects $6 \%$ to $10 \%$ of all pregnant women and other than anemia is the most common hematologic disorder in pregnancy.

Thrombocytopenia in pregnancy may occur secondary to a variety of causes ranging from benign disorders to syndromes associated with significant morbidity. Other causes of thrombocytopenia in pregnancy are rare such as type II von Wiillebrand Disease (vWD), and disseminated intravascular coagulation. Most of these occur during specific periods of gestation, although these periods may sometimes overlap. On occasion, patients may present with a constellation of symptoms that reflect characteristics of more than one disorder. While some of these are not associated with adverse pregnancy outcomes, others are associated with substantial maternal and/or neonatal morbidity and mortality.

The challenge to the clinician is to weigh the risks of maternal and fetal bleeding complications against the benefits of diagnostic tests and interventions.

An accurate diagnosis and risk assessment in the antenatal period are essential for developing specific plans for any antenatal interventions and for management of delivery and the postpartum periods, and the neonate.

Management of pregnant women with platelet disorders requires a multidisciplinary approach and close collaboration between the obstetric and haematology teams. Also in developing countries like India, diseases like Malaria and Dengue which are uncommon in other parts of the world, add to the morbidity of the condition and prove to be challenging and pose a management dilemma.

In this modern era of component therapy and advances in the field of blood and blood products has helped to manage the respective deficiency of blood components in the cases. So blood and blood products transfusion especially platelet transfusion has proved to be a boon to the patients of pregnancy associated thrombocytopenia.

Funding: No funding sources

Conflict of interest: None declared

Ethical approval: The study was approved by the institutional ethics committee

\section{REFERENCES}

1. Boehlen F, Hohlfeld P, Extermann P, Perneger TV, deMoerloose P. Platelet count at term pregnancy: a reappraisal of the threshold. Obstet Gynaecol. 2000;95:29

2. Sainio S, Kekomäki R, Riikonen S, Teramo K. Maternal thrombocytopenia at term: a populationbased study. Acta Obstet Gynaecol Scand. 2000;79:744.

3. Parnas M, Sheiner E, Shoham-Vardi I, Burstein E, Yermiahu T, Levi I, et al. Moderate to severe thrombocytopenia during pregnancy. Eur J Obstet Gynecol Reprod Biol. 2006 Sep-Oct;128(1-2):163-8.

DOI: $10.5455 / 2320-1770$. ijrcog20141214

Cite this article as: Katke RD, Gohil DP.

Thrombocytopenia during pregnancy: an institutional based study. Int J Reprod Contracept Obstet Gynecol 2014;3:947-51. 